\title{
Lexical Frequency and Frequency of Co-Occurrence Predict the Use of Embedded-Language Islands in Bilingual Speech: Adjective-Modified Nominal Constituents in Russian-German Code-Mixing
}

\author{
Nikolay Hakimov \\ Assistant Professor of Slavic Linguistics, Department of Slavic Studies, \\ University of Bamberg, Bamberg, Germany \\ Nikolay.Hakimov@uni-bamberg.de
}

\begin{abstract}
This article explores the role of usage frequency in the structure of language mixing by the application of corpus-linguistic and statistical methods. The goal of the study is to reveal that the frequency of a lexical item and the frequency with which it occurs with other items account for its use in bilingual speech. To achieve this goal, I analyze German monolingual and German-Russian mixed adjective-modified nominal constituents in otherwise Russian discourse in a corpus of Russian-German bilingual speech collected from fluent bilinguals in Russian-speaking communities in Germany. My findings show that many of German nominal constituents, also called embedded-language islands, are recurrent A-N combinations. However, in the absence of sequential associations between the involved words, the adjectives may be realized in Russian or in German. In light of this evidence, I suggest two mechanisms underlying the production of embedded-language islands: retrieval of a multiword chunk and co-activation.
\end{abstract}

\section{Keywords}

code-mixing - embedded-language island - frequency - multiword chunk co-activation - Russian - German 
Already the first systematic studies of bilingual speech such as Pfaff (1979) and Poplack (1980) report extensive use of nouns and nominal constituents of one of the bilinguals' languages in the context of the other. Such patterns of language mixing are particularly frequent in insertional code-mixing. In this type of language mixing, elements of one language, such as lexical stems, are inserted into the grammatical frame defined by the other language. Following Myers-Scotton's (1993) proposal, the grammatically dominant language is labeled as the matrix language, whereas the other language is referred to as the embedded language. In this terminology, nouns of the embedded language are inserted in the matrix language grammatical frame. Combinations of noun insertions with grammatical structures of the dominant language are labeled as mixed constituents and result from the process of morphosyntactic integration into the dominant language. Mixed constituents are viewed as the default case in insertional code-mixing (cf. Myers-Scotton, 2002: 20). Not infrequently, however, longer constituents, consisting of the other-language lexical stems accompanied by the grammatical markers of the same language, are inserted into sentence frames set by the dominant language. Insertions of this type are referred to as embedded-language islands (Myers-Scotton, 1993). The motivations behind the emergence of embedded-language islands in bilingual speech are controversially debated. While Myers-Scotton and Jake (1995) suggest that embedded-language islands appear owing to insufficient congruence among the participating languages, Backus (2003) argues that an embedded-language island is a lexical unit, or chunk, which is retrieved from memory as a whole. According to his definition, multiword units are conventionalized expressions, which are distinguished by idiomaticity or high usage frequency. However, these diagnostics might not always be applicable because some embedded-language islands have compositional meanings, while others occur only on rare occasions. In this context, the main objective of this paper is to put Backus' (2003) unit hypothesis to the test.

Arguing that idiomatic expressions should occur with sufficient frequency in the input, in order to be memorizable for language users, I propose to redefine multimorphemic units by relying solely on usage frequency as a diagnostic. This approach allows for an examination of occurrence frequency as a factor contributing to the distribution of embedded-language islands in bilingual speech. The main hypothesis of this paper is that the occurrence 
frequency of a multiword expression, but also the individual frequencies of this expression's parts account for the emergence of embedded-language islands in code-mixing.

As a case study, this paper investigates variation in code-mixing in the context of adjective-modified nominal constituents. In bilingual speech, as in the speech of Russian-speaking communities in Germany, embedded-language nouns combine with adjectives either of the matrix language, or of the embedded language, to yield two different kinds of structure, namely mixed adjective-modified nominal constituents, as ogromnyj spielplatz 'huge playground' in (1), ${ }^{1}$ and embedded-language nominal constituents, as alleinerziehende mutter 'single mother' in (2).

(1) Russian-German in Germany

$\begin{array}{lllll}\text { esli } & \text { my } & \text { xodim } & v & \text { stadtgarten, } \\ \text { if } & \text { we } & \text { go:PRS1PL } & \text { to } & \text { city_garden }\end{array}$

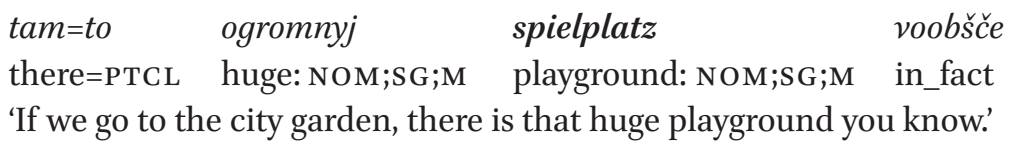

(Fr-110801-2)

(2) Russian-German in Germany

kogda vidjat alleinerziehende mutter, èto

when see:PRS3PL single:ACC/NOM;SG;F mother[SG;F] HES

\begin{tabular}{|c|c|c|}
\hline nicht & so & berut. \\
\hline NEG & so & take:PRS3PL \\
\hline
\end{tabular}

This syntactic context offers a convenient locus of variability for ascertaining the relevance of frequency-based factors for the emergence of embedded-language islands and for processes involved in production of naturally occurring bilingual speech.

1 In the examples and tables, the words from another language are in bold. 
Relying on corpus-linguistic evidence that co-occurrence frequency can model semantic unity (e.g., Heylen and De Hertog, 2014; Schneider, 2016; Stefanowitsch and Flach, 2016), I will demonstrate in what follows that co-occurrence frequency accounts for embedded-language islands corresponding to multimorphemic units in the lexicon. As embedded-language islands without unit status also occur, I will argue on the basis of the evidence presented below that embedded-language islands emerge because two mechanisms are at work in online production: (a) activation of a represented lexical chunk and (b) successive co-activation. A speaker may thus retrieve a multimorphemic chunk as a unit, or activate the representation of an adjective, co-activate the representation of a noun and retrieve them successively.

The study draws on a corpus of Russian-German bilingual speech recorded in Germany. Russian and German, being genetically related languages, share a number of characteristics in their morphosyntax. As fusional languages, they rely on sets of inflectional classes. The canonical structural configurations of adjectival modification in both languages are similar. Typically, modifying adjectives precede their head nouns and agree with them in gender, number and case. Because German and Russian exhibit more similarities than differences in attributive modification, the two languages offer a solid testing ground for predictions about the structure of code-mixing, which are beyond the area of grammatical incongruence.

The paper is organized as follows. The next section will outline the literature on the insertion of nouns and nominal constituents in code-mixing and summarize the proposed explanations for the occurrence of embedded-language islands. Section 3 provides a brief overview of the patterns of adjectival modification in Russian and German. Section 4 describes the bilingual corpus and the patterns of attributive modification in the examined data set. Section 5 introduces and analyses usage-based factors underlying the variation in code-mixing patterns, these factors include frequency of the adjective, frequency of the noun and frequency of their co-occurrence. Section 6 presents the results of the statistical analysis, which are then summarized and discussed in the final sections.

\section{Insertion of Nouns and Adjective-Modified Nominal Constituents in Bilingual Speech}

As attested in numerous corpora of bilingual speech, bilingual speakers regularly use nouns and nominal constituents from one of their languages in clauses framed by the other language. The frequent use of these structures in bilingual 
speech has motivated extensive research into patterns of code-mixing along various theoretical and methodological lines (e.g., Cantone and MacSwan, 2009; Parafita Couto, Deuchar and Fusser, 2015; Poplack and Meechan, 1995). However, the existing literature is often controversial with regard to the nature of the inserted structures. Particularly debated are the mechanisms behind the emergence of inserted nominal constituents in bilingual speech.

\subsection{Noun Insertion}

Noun insertion has been reported to be the most frequent pattern of code-mixing (e.g., Backus, 1992; Berk-Seligson, 1986; Boumans, 1998; Halmari, 1997; Haust, 1995; Hlavac, 2003; McClure, 1977; Myers-Scotton, 1993; Nortier, 199o; Poplack, 1980). Researchers who treat noun insertion as borrowing (Poplack, Sankoff and Miller, 1988; Sankoff, Poplack and Vanniarajan, 1990; Treffers-Daller, 1994; van Hout and Muysken, 1994) also find that nouns are borrowed extremely often. According to Muysken, "[n]ouns are the class of elements borrowed par excellence and also the prime example of insertion under categorical equivalence" (Muysken, 2000: 75).

Although scholars generally agree that nouns are prone to being selected in code-mixing because of their semantic nature, opinions differ with regard to the precise properties of their meanings that make them so susceptible to code-mixing, or borrowing. Van Hout and Muysken (1994) attribute this tendency to the property of nouns to express culturally loaded concepts. Backus (1996) and Field (2002) explain the same phenomenon by a high specificity of nouns' meanings. Nouns are likely to be involved in code-mixing and borrowing at high rates because their meanings are often very specific. Following Langacker (1987: 299-302), Backus relates the specificity of an element's meaning to an element's autonomy and thus its morphosyntactic property to "stand on [its] own" (Backus, 1996: 122). The view that most nouns are autonomous elements concurs with another distinctive property of nouns, namely their high syntagmatic freedom (Backus, 2013). The ability of nouns to fill the slot in virtually any configuration of the noun phrase has obviously lead Boumans (1998: 221) to reason that noun insertion is an unconstrained process. In this context, we conclude that semantic and structural factors behind this process interact, particularly in a situation of intense contact (cf. van Hout and Muysken, 1994).

\subsection{Insertion of Nominal Constituents}

Inserted nominal constituents and fully-fledged noun phrases regularly occur in mixed clauses as well, though at a lower rate than nouns (Backus, 1992; BerkSeligson, 1986; Hlavac, 2003; Haust, 1995; Poplack, 1980). Plentiful studies of 
bilingual speech have documented that insertion of fully-fledged noun phrases may be less common than the insertion of nominal constituents (Backus, 1992; Boumans, 1998: 203-205; Deuchar, 2006; Gardner-Chloros, 1991; Hlavac, 2003: 93; McClure, 1977; Muhamedowa, 2006: 77-88; Poplack, 1980); however, there are exceptions to this trend (e.g., Treffers-Daller, 1994). These studies also demonstrate that insertions of A-N combinations, or adjective-modified noun phrases (henceforth ANP constituents), prevail over insertions of nominal constituents with other syntactic configurations. Crucially, bilingual speakers insert ANP constituents regardless of the A-N order that their languages take.

The languages in contact may share the A-N order, like German and Hungarian, in which modifying adjectives precede nouns, for instance:

(3) German (dialect)-Hungarian (Szabó, 2010: 373)

$\begin{array}{ccccl}. . & \text { ihr hat } & \text { szociális } & \text { villany } & \text { ghabt } \\ \text { 2PL } & \text { have:PRS2PL } & \text { social } & \text { electricity } & \text { have:PTCP } \\ \text { '...you have had a social-benefit rate for electricity.' } & \end{array}$

Here, the noun and the adjective of the inserted Hungarian constituent szociális villany 'social electricity' follow the same word order as its German counterpart sozialer Strom 'social:NOM.SG.M electricity[SG.M]', namely A-N. The inserted constituent has Hungarian internal structure: the adjoined adjective szociális 'social' is uninflected and complies with the requirements of Hungarian grammar. When word orders in the adjective-modified noun phrases of the contact languages differ, ANP insertions also occur. This is the case, for example, in Mandinka-English code-mixing.

(4) Mandinka-English (Haust, 1995: 176)

$\begin{array}{llllrlll}a & \text { la buyo } & \tilde{n} \text { in } & \text { mu } & \text { single } & \text { room-oo } & \text { le } & t i \\ \text { 3SG GEN house.DET } & \text { DEM COP } & & \text {-DET } & \text { PTCL COP } \\ \text { 'This house of his is a single room.' } & & & \end{array}$

Mandinka requires the N-A order, whereas English uses the A-N order as the canonical pattern. In (4), the English ANP constituent single room is embedded in an otherwise Mandinka clause and takes the Mandinka determiner suffix $-o(o)$.

The status of inserted adjective-modified nominal constituents is a matter of much controversy. Some researchers regard these constituents as part of the lexicon, while others consider them pertinent to grammar and thus treat them 
as inserted nominal constituents. For example, Gardner-Chloros (1991) considers French ANP constituents in Alsatian discourse as lexical switches. Her corpus, collected in Strasbourg, abounds in inserted ANP constituents, most of which, including portes ouvertes 'open day' (ibid.: 141) and résidence secondaire 'holiday home' (ibid.: 141), pattern according to the N-A order, but the corpus also contains a limited number of insertions following the A-N order, such as jeune homme 'young man' (ibid.: 139). A similar position is taken by Sankoff, Poplack and Vanniarajan (1990) in their analysis of English ANP constituents in otherwise Tamil sentences. Such constituents, including arranged marriage, Indian women or supernatural being, are regarded as compound borrowings because they never combine with English function words in mixed clauses. Muysken (2000: 78-81) argues against this analysis and suggests that these structures are inserted NP s and thus a matter of syntax rather than the lexicon.

The proponents of the matrix language frame (MLF) model (Myers-Scotton, 1993; Myers-Scotton and Jake, 1995) take a position similar to Myusken's (2000). According to this model and its more recent extensions, A-N combinations in focus are viewed as embedded-language islands because they are "full constituents consisting only of Embedded Language morphemes occurring in a bilingual CP that is otherwise framed by the Matrix Language" (Myers-Scotton, 2002: 139). The internal structure of an embedded language constituent corresponds to the norms of the language that provides the morphemes, i.e., the embedded language. The quoted above examples support this observation.

The various approaches exhibit even sharper differences with regard to the assumptions underlying the emergence of the examined structures in bilingual speech.

\subsection{Explanations for the Emergence of ANP Insertions}

One of the first explanations for the insertion of ANP constituents was set out in the matrix language frame model (Myers-Scotton, 1993). As mentioned above, the insertions in focus are embedded-language islands, whose internal structure fulfils the requirements of the embedded language. Myers-Scotton and Jake (1995) contend that an embedded-language island may appear if "lemmas", defined as abstract entries in the mental lexicon that underlie lexemes, lack congruence in one of three aspects. These aspects include semantic/pragmatic features, predicate-argument structure and morphological realization patterns. However, this approach cannot pinpoint which specific aspect motivates the occurrence of an embedded-language island in a given context. This consideration may well have led some scholars to restrict their analyses of embedded-language islands to a specific type of congruence. For example, Deuchar (2005) argues that only grammatical rather than semantic 
congruence restricts the possibilities of switching. In the case of ANP constituents, congruence pertains to the word order within the constituent. Reasoning along these lines, we can explain the occurrence of embedded-language islands structured as ANP constituents in constellations of languages with a word-order non-equivalence in the examined structure. This applies to such language pairs as Moroccan Arabic and Dutch, or Mandinka and English, but this explanation will not hold for languages employing an identical A-N order, such as German and Hungarian, or Tamil and English.

Following the tenets of cognitive grammar, Backus (1996, 1999, 2003) elaborates the idea that idiomatic expressions are one type of multi-morphemic lexical units which are inserted into a matrix language clausal frame. Other types of lexical units include multi-morphemic elements that exhibit morphosyntactic irregularities or high usage frequency. Given a rich memory for language (Bybee, 2006, 2010; Langacker, 1987; Tomasello, 2003), any multi-morphemic unit would be considered as stored in the mental lexicon and retrieved from it during on-line production as a whole. This leads Backus $(1999,2003)$ to hypothesize that every embedded-language island is a unit. ${ }^{2}$ Yet, bilingual corpora contain embedded-language islands that are morphosyntactically regular, semantically compositional and infrequent in use. If such sequences do not count as multi-morphemic units, their occurrence in bilingual clauses would be counterevidence to the "unit" hypothesis. In fact, instances of this kind have been documented in bilingual-speech corpora. One example is the French word combination toupie jaune 'yellow spinning top', which occurs in an Alsatian sentence (GardnerChloros, 1991: 133). Interestingly, in further discourse the same speaker realizes the adjective in Alsatian and produces the mixed constituent gäls toupie 'yellow spinning top'. Crucially, counterexamples like this would not refute the "unit" hypothesis if they turn out to be negligible in amount. Hence, the obvious way to examine the "unit" hypothesis is to put it to a statistical test.

The "unit" hypothesis is corroborated by Boumans' (1998: 386-387) observation that Dutch nouns in otherwise Moroccan-Arabic sentences are regularly modified by Dutch attributive adjectives, but virtually never occur with Moroccan-Arabic adjectives. He relates this asymmetry to the existence of collocational ties between nouns and attributive adjectives, which are obviously not restricted to idiomatic expressions. Boumans suggests that "[i]f

2 In her treatment of embedded-language islands, Myers-Scotton (2002) discusses Backus' idea of holistic units (p. 141) and acknowledges frequency of co-occurrence and collocational ties, alongside grammatical constraints, as possible motivations behind the emergence of embedded-language islands (p. 153). 
the existence of collocational ties between lexical units in the mental lexicon accounts for the co-occurrence of EL [=embedded-language] words, the total absence of such ties may perhaps explain the observed constraints on the co-occurrence of ML [=matrix-language] and EL lexical items" (ibid.: $386-387$ ). This means that an approach that aims at explaining the emergence of embedded-language islands in bilingual speech has also the potential to clarify the intricacies of mixed constituents. This idea provides a starting point for the subsequent study: in order to prove the existence of collocational ties that wield words together to become units, we need to compare ANP constituents consisting of embedded-language words with mixed ANP constituents.

In a nutshell, structural and semantic explanations have been suggested to account for the emergence of embedded-language A-N combinations in code-mixing. A structural explanation builds on the notion of grammatical incongruence between the lemmas of the involved languages in the realization patterns of ANP constituents (Myers-Scotton, 2002; Myers-Scotton and Jake, 1995). That is, non-equivalence in the noun-adjective order can trigger the occurrence of an embedded-language island, realized as an adjective-modified noun phrase (cf. Deuchar, 2005). This explanation does not apply to languages in contact with an identical A-N order. Other scholars (e.g., Poplack and Meechan, 1995) contend that at least some embedded nominal constituents are idiomatic expressions. Although plausible, this explanation will fail to account for embedded A-N combinations without idiomatic meanings. Yet others (e.g., Backus, 1996; Boumans, 1998) suggest that nouns frequently used with specific adjectives are good candidates for ANP insertions, since in bilingual production they may be accessed and retrieved as holistic units, or chunks. However, as bilingual speech is highly variable, not every inserted A-N combination would necessarily qualify as a unit. Also, code-mixing data alone will not suffice for obtaining unequivocal evidence for the existence of collocational ties. Hence, we need to examine collocations in both bilingual and monolingual speech. Before I embark on this analysis, I outline the characteristics of adjectival modification in German and Russian below.

In languages of the world, an attributive adjective either precedes or follows the noun it modifies, and the adjective is usually adjacent to the head noun (Dryer, 2013). The canonical pattern for attributive adjectives in German and in 
Russian is to occur left adjacent to the head noun and to agree with it in case, number and gender (see Švedova, 2005[1980]a: 1303, for Russian; Eisenberg, 1999: 232, for German), for instance:

(5) German (Zifonun et al., 1997: 1991)

$\begin{array}{lll}\text { ein } & \text { klein-es } & \text { grün-es } \\ \text { ART[NOM.SG.N] } & \text { little-NOM.SG.N } & \text { green-NOM.SG.N } \\ \text { Männchen } & & \\ \text { little.man[NOM.SG.N] } & & \\ \text { 'a little green man' } & & \end{array}$

The adjectives kleines 'little' and grünes 'green' in (5) share the features of case, number and gender with the subsequent head noun Männchen little man'. This pattern of adjectival modification is also common in Russian, for example:

\section{(6) Russian}

$\begin{array}{lll}\text { malen'k-ij } & \text { zelën-yj } & \text { čeloveček } \\ \text { little-NOM.SG.M } & \text { green-NOM.SG.M } & \text { little.man[NOM.SG.N] } \\ \text { 'a little green man' } & & \end{array}$

In (6), the features of gender, number and case are spread from the noun čeloveček 'little man' to its attributes malen'kij 'small' and zelënyj 'green', which immediately precede the noun. ${ }^{3}$ Another similarity between German and Russian, as can be seen in (5) and (6), is the use of inflectional morphology on nouns and adjectives: the two languages draw on formatives combining case, number and gender.

Post-nominal modification applies to attributive adjectives in both German and Russian, though at different rates. While its use in German is restricted to some specific cases (Auer, 2007a; Dürscheid, 2002: 67-68), its use in Russian is widespread, particularly in the spoken register (Lapteva, 1976: 207, 213; Zemskaja, 1987:152). Another characteristic feature of Russian adjectival modification is the ability of adjectives to take positions detached from their noun heads. Detachment applies to modifying adjectives in both pre- and postposition and depends on the information structure of a clause and discursive

3 In the inflection of the noun, the feature of animacy is marked in singular masculine nouns (and some neuter nouns) and all plural nouns in the accusative case. 
TABLE 1 Patterns of adjectival modification in German and Russian. The bracketed ticks stand for possible, but highly constrained patterns, as reported in descriptive grammars (Eisenberg, 1999; Lapteva, 1976; Švedova, 2005[1980]a, b)

\begin{tabular}{cccc}
\hline & Pattern & Russian & German \\
\hline 1 & {$[$ A-INFL N-INFL] } & $\checkmark$ & $\checkmark$ \\
2 & {$[$ N-INFL A-(INFL) } & $\checkmark$ & $(\checkmark)$ \\
3 & {$[$ A-INFL ... N-INFL $]$} & $\checkmark$ & $(\checkmark)$ \\
4 & {$[$ N-INFL ... A-INFL $]$} & $\checkmark$ & \\
\hline
\end{tabular}

requirements (Miller and Weinert, 1998: 167; Zemskaja, 1987: 153). In contrast, noun phrases in German are split only on rare occasions, such as topicalization, which is a highly restricted pragmatic condition (Eisenberg, 1999: 234). As the bilingual data to be discussed below do not contain instances of German split noun phrases, I will neglect them in the current outline.

The overview of German and Russian syntactic patterns of adjectival modification demonstrates that important similarities, but also notable differences exist between the two languages. The patterns of adjectival modification are summarized in Table 1. Modifying adjectives can take both positions adjacent to their head nouns. While the prenominal position is canonical for attributive adjectives in German, attributive adjectives in Russian appear to occur in both positions. Of the two patterns, the postnominal position is particularly frequent in colloquial Russian. In German, it is restricted to either specific lexical items or special contexts. The distance between the noun head and the attributive adjective is an important parameter in attributive modification in Russian, but not in German. Overall, the two languages overlap in the use of pattern [A-INFL N-INFL] and in the aforementioned marginal cases, associated with postposition. However, Russian allows for a greater variability of modification patterns than German.

Based on the obvious commonalities and pronounced differences, we can predict that in Russian-German code-mixing, bilingual speakers will draw on the A-N pattern, common to both languages, much more frequently than on other available patterns. Additionally, in the cases in which Russian is the matrix language, Russian adjectives will pre- or post-modify German noun insertions, whereas German adjectives in German ANP insertions will pre-modify their German head nouns, in compliance with the German canonical pattern. In order to test the reliability of these predictions, I will analyze the distribution of the two types of insertion in the bilingual corpus. 


\subsection{Corpus}

This study draws on a corpus of Russian-German bilingual speech recorded amongst Russian-speaking communities across Germany (Freiburg im Breisgau, Hanover, Lahr/Black Forest) (cf. Hakimov 2016a, 2016b, to appear). These communities emerged as a result of ethnic Germans' repatriation from the former Soviet Union. The official name of this ethnic group is russlanddeutsche (Spät-)Aussiedler 'Russian-German late repatriates' (Brehmer, 2007; Meng, 2001). The participants of the study included 21 young adults belonging to this group and aged between 18 and 35 years old. All of them, except one, were born in the former Soviet Union and left their countries of origin in their childhood. Owing to their early age at immigration, they can be regarded as the so-called intermediate generation (cf. Backus, 1996: 58). Though five of these speakers were exposed to German before repatriation, Russian was the first language that they acquired (Dietz, 2006; Riehl, 2017). The age of acquisition of German, as measured by the age of immigration to Germany, varies: four speakers began learning German before the age of seven, fifteen started between eight and twelve, and one speaker began at the age of fifteen. All but one participants has lived in Germany for at least ten years prior to the data collection. The exception participant has resided in Germany for only three years, but she started learning German before her immigration and was living in a half-German family, being richly exposed to German. The other control factor for bilingual capacity is school education in Germany. That is, the subjects had either finished school in Germany or were still attending school there. These selection criteria ensured that all informants were fluent bilinguals.

The total size of the corpus is approximately 28 hours of recorded speech. One half of the corpus includes casual conversations that involved one of the subjects and their peers or family members. The other half of the corpus contains informal group interviews conducted by the researcher with those subjects who were unwilling to record their private conversations. The interviews were carried out in unstructured peer groups consisting of at least two subjects, who were well familiar with each other. This strategy enabled the researcher to maintain the naturalness of interaction. Another strategy aiming at the same end was for the interviewer himself to engage in language mixing. Importantly, the subjects were not informed of the aim of the research. The relevant information regarding the participants' language biographies was made available after the recording.

Adjective-modified nominal constituents containing German noun insertions were extracted from the bilingual corpus. Modification of Russian nouns 
by German adjectives is almost non-existent in Russian-German bilingual speech, ${ }^{4}$ despite the wide presence of German adjective insertions in Russian predicative constructions (cf. Deuchar, 2005, on a similar case in Welsh-English code-mixing).

\subsection{Adjective-Modified Nominal Constituents in the Russian-German Bilingual Corpus}

Noun modification by attributive adjectives in Russian-German bilingual sentences in my corpus shows two general patterns: German adjectives modify German nouns in otherwise Russian sentences, or Russian adjectives modify German noun insertions. All but one well-formed German ANP constituents follow the canonical German A-N order, whereas Russian attributive adjectives are placed left- or right-adjacent to their German noun heads, which is in line with the outlined Russian configurations.

\subsubsection{German ANP Constituents in Russian}

Following Muysken's (2000) typology, German A-N combinations occurring in Russian sentences qualify as maximal insertions (cf. Auer, 2014) and thus represent a case of insertional code-mixing. In only one instance, a German ANP constituent is classified as an example of alternational code-mixing. Insertion of German adjective-modified noun phrases are the most frequent case in the corpus: 71 ANP constituents were identified, which correspond to 65 lexical types. As these phrases invariably lack German determiners, ${ }^{5}$ only those of them count as fully-fledged which are also used without determiners in German. An example of such an insertion is the noun phrase nächstes Jahr 'next year'. Others, as in the example below, are not fully-fledged.

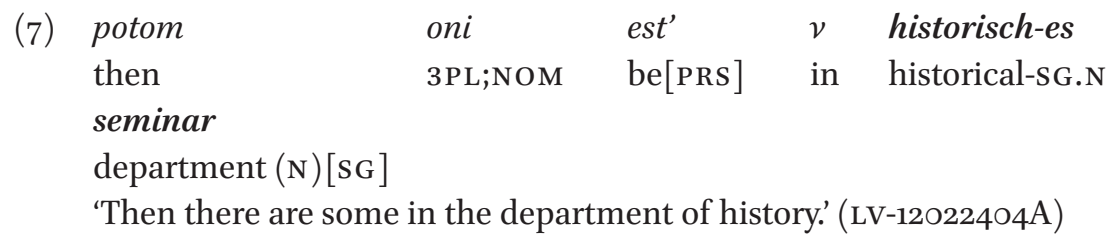

4 In a sample of more than a thousand mixed items, only one instance of German adjective insertion in a Russian noun phrase was documented: ètix asoziale nemtsev 'these antisocial Germans'.

5 The only exception to this is the insertion of the German phrase mein ganzer Pony 'my whole fringe' (LS-110517La), in which the pronominal adjective mein 'my' occupies the determiner position. 
The German determinerless nominal constituent historisches Seminar 'historical department' is embedded in a Russian prepositional phrase. In a German sentence, it would be preceded by a definite article because it refers to a definite object. The use of a definite article would require inflecting the adjective according to the weak inflectional class. However, the suffix -es on the adjective historisch 'historical' is chosen from among a strong inflectional class, which is reserved in German for determinerless adjective-modified noun phrases. Of 70 German adjectives, 60 take one of the three inflectional suffixes of the strong declension class: the suffix $-e$ marks agreement with a feminine or plural noun, the suffix -er marks agreement with a masculine noun and the suffix -es marks agreement with a neuter noun. Apart from the categories of gender and number, these suffixes also express case. In monolingual speech, the first two suffixes are exponents of the nominative, or accusative case, and the suffix -er is an agreement marker of the nominative case. However, speakers select these agreement suffixes even when the case projected on the slot in which they are inserted together with their head nouns is neither nominative, nor accusative. For instance, the Russian locative-directional preposition $v$ 'in' in (7) assigns the Russian prepositional/ locative case to the noun phrase since the whole prepositional phrase has a spatial meaning. The case that expresses spatial relations in German is the dative, and the inserted noun phrase should be marked for the dative case. However, the data show that case distinctions are neutralized when case is projected on German ANP constituents in otherwise Russian sentences. Despite the intricacies pertaining to the choice of the declension class and case marking, we can contend that within the inserted adjective-modified nominal constituents, such as in (7), the gender and number agreement is maintained. Hence, their internal structure is coherent and conforms to that of the embedded language, i.e., German. This fact allows us to consider suchlike insertions as embedded-language islands.

Considering the differences in the configurational structure of adjective-modified noun phrases in German and in Russian, I consider the pervasive use of the German strong declension class with the adjectives in these constituents as a compromise strategy. Bilingual speakers omit determiners, which are mandatory in German but lacking in Russian, and select suffixes of the strong declension class, which applies to German determinerless noun phrases. Although this strategy involves the neutralization of case distinctions, it provides for increased overall similarity between the noun phrase configurations in the involved languages. Additionally, it enhances the unambiguousness of agreement marking between the noun and the adjective because the suffixes of the strong declension class exhibit the lowest degree of syncretism among the three declension classes (Wurzel, 1984). In other words, structural 
TABLE 2 Variation in German A-N insertions in Russian sentences according to their word order and internal structure

German word order

Deviant word order

German internal structure

Aberrant internal structure
61

5
2

3

similarity between the matrix language and the embedded language increases, while the structural integrity of the inserted constituent remains untouched.

The analysis of German ANP insertions as embedded-language islands is based on their formal properties. In order to count as an embedded-language island, i.e., a well-formed German constituent, an ANP constituent has to be structured according to German grammatical conventions. If a constituent exhibited a deviant internal structure or an aberrant word order pattern, it was not analyzed as an embedded-language island; its parts were considered as consecutive insertions. Table 2 provides a classification of German A-N combinations in otherwise Russian discourse and their usage rates in the bilingual corpus.

As can be seen from the table, the ANP constituent insertions with the word order and internal structure complying with German grammatical conventions make up the largest group of the four possible types. The phrases historisch-es Seminar 'historical-sG.N department', klein-er Stern 'small-sG.M star', kriminell-e Jugendlich-e 'criminal-PL youth-PL' and süß-e Grußkarte 'sweet-sG.F greeting card' exemplify this group. As argued above, the inflectional formatives on adjectives in bilingual sentences combine gender and number, although in monolingual German usage they also express case. Nevertheless, the A-N combinations in this group correspond to well-formed German nominative-marked noun phrases and thus qualify as embedded-language islands (for more details, see Hakimov, to appear).

The next largest group includes five German A-N combinations with the canonical German word order and a deviant internal structure. If we assume that the adjectives in these combinations are inflected in accordance with the strong declension, just as the adjectives of the largest group, we shall state an inconsistent use of inflectional morphology. Four adjectives in this group are inflected and one adjective is bare. The combinations with inflected adjectives include gut-en Wohngegend 'good-ACC.SG.M neighbourhood(F)[NOM.SG]', richtig-e Italien 'real-SG.F Italy(N)', römisch-e Reich 'Roman-SG.F empire(N)[SG]', zweit-e Auto 'second-sG.F car(N)[SG]'. This analysis considers the nouns' gender features as they are realized in monolingual German (for more details, see 
Hakimov, to appear). Interestingly, in all but the first combination the noun's gender value corresponds to the gender value of the noun's Russian equivalent: the German neuter nouns Italien 'Italy', Reich 'empire' and Auto 'car' have feminine counterparts in Russian, namely Italija, imperija and mašina. Since the gender features of the nouns are apparently transferred from Russian, we cannot regard these combinations as well-formed embedded-language islands. The only bare form attested is the adjective typisch, which is part of the A-N combination typisch Zwilling 'typical Gemini'.

The ANP constituents that deviate from monolingual German usage in their word order pattern and internal structure are Italien richtig-e 'Italy $(\mathrm{N})$ real-SG.F', Lesezeichen [...] magnetisch-e 'book-mark(N)[SG] magnetic-SG.F', and polen-litauisch-e [...] Union 'Poland-Lithuanian-SG.F Commonwealth(F) [sG]'. The noun Lesezeichen of the phrase Lesezeichen [...] magnetische 'magnetic book-mark' is reminiscent of the earlier discussed noun Italien 'Italy' in that it also seems to share the feminine gender value with its Russian equivalent zakladka. As for the phrase polen-litauische [...] Union 'Polish-Lithuanian Commonwealth', the adjective polen-litauisch 'Poland-Lithuanian', which is non-existent in German, may be regarded as a result of processing difficulties, namely a concurrent activation of similar German forms Polen-Litauen 'Poland-Lithuania' and polnisch-litauisch 'Polish-Lithuanian', which collocates with the noun Union 'Commonwealth'. Importantly, all of the phrases in this group follow Russian word-order conventions.

The ANP constituents of the smallest group correspond to the German grammatical conventions in their internal structure, but in their syntax they follow Russian patterns. The only instances include the phrases offen-e [...] Lesung 'open-SG.F reading(F)[sG]' and Mama [...] modern-e 'mother(F)[sG] modern-SG.F'. Overall, eleven A-N combinations, which correspond to barely $14 \%$ of all the instances, deviate in at least one of the examined features from the corresponding combinations in monolingual German. As these instances cannot be regarded as embedded-language islands on these grounds, and are better conceived of as subsequent insertions, we cannot draw on them when testing the hypotheses explaining the emergence of embedded-language islands.

4.2 .2

Mixed ANP Constituents Consisting of German Nouns and Russian Attributive Adjectives

As mentioned earlier, German noun insertions in Russian-German bilingual sentences are regularly modified by Russian attributive adjectives, though not as often as by German adjectives. The corpus contains 41 instances of 
this type. According to Russian grammatical conventions, when modifying a noun, Russian attributive adjectives may be placed pre- and post-nominally. Although both patterns occur in the corpus, pre-nominal modification overwhelmingly outnumbers post-nominal modification by 35 instances to 5 , a difference of 7 to 1 . The example below illustrates this type.
(10) na sledujuščej haltestelle vy dolžny vylezti on next:PREP;SG;F stop(F)[SG] 2PL;NOM obliged:PL get_off:INF 'You should get off at the next stop.' (LS-101221J)

In (10), the Russian attributive adjective sledujuščej modifies the German noun insertion Haltestelle 'stop' in pre-nominal position. The Russian inflectional suffix of the adjective -ej expresses the feminine gender and the prepositional/locative case. The whole noun phrase is prepositional/locative-marked because it is headed by the preposition $n a$ 'on', governing the prepositional/ locative case. With regard to the gender of the noun phrase, we may well assume by considering the German noun's inherent gender value and the gender marked by the Russian suffix that the noun and the adjective share the feminine gender value. It is impossible to decide however whether the form Haltestelle is an uninflected noun, as it is in German, or whether the stem-final schwa of the German noun is the Russian inflectional suffix of the prepositional/locative case, i.e., Haltestell- + -e.

In five instances in my corpus, Russian adjectives modify German noun insertions post-nominally, for example:

$\begin{array}{llllll}\text { (11) A: } & a \quad \text { podružki } & \text { u } & \text { tebja } & \text { russkie } & \text { ili } \\ & \text { and friend:NOM;PL } & \text { with } & \text { 2SG;GEN } & \text { Russian:NOM;PL } & \text { or } \\ & \text { nemeckie? }\end{array}$

German: NOM;PL

'And are your friends Russian or German?'
B: $n u$ unterschiedlich, mischmasch celyj
PTCL variable jumble(M)[SG] whole:NOM;SG;M
'Well, it depends - a whole jumble.' (Fr-110801-1)

Here, the mixed noun phrase consists of the German noun Mischmasch 'jumble' and the Russian adjective celyj 'whole' modifying the noun post-nominally. The noun phrase is marked for the nominative case and the masculine 
gender. These features are realised on the adjective in the form of the inflectional suffix $-y j$ and on the German noun non-overtly, since the nominative case is zero-marked on masculine singular nouns ending in a consonant and coincides with the bare stem. The only occurrence of a mixed noun phrase with a pre- and a post-nominal Russian adjective in my corpus is the phrase

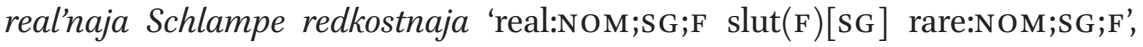
in which the German feminine noun with a stem-final schwa is handled as a Russian noun belonging to a class of indeclinable nouns, reserved for loan words.

The corpus data reveal that Russian attributive adjectives, when modifying inserted German nouns, occur in the immediate pre-nominal position in $85 \%$ of the instances. The figure is comparable with the rate at which German attributive adjectives immediately precede their German noun heads in the inserted nominal constituents, i.e., $93 \%$ of the occurrences in the bilingual corpus. It is interesting that although Russian, being the matrix language in the analyzed clauses, permits several word order patterns for modification, the Russian-German bilingual speakers prefer a pattern that is common to both languages.

\subsubsection{Frequencies of German ANP and Noun Insertions in the Corpus}

In the bilingual corpus, German items such as single nouns as well as adjective-modified nominal constituents are encountered in otherwise Russian sentences at varying rates. As such, a specific German A-N combination appears in Russian discourse only once, but a few combinations occur in the corpus more often. Although the combination baltische Länder 'Baltic states' is found in the corpus three times, each of its instances appears in a conversation passage of one minute. Among combinations that occur in Russian discourse two times are Badische Zeitung 'Baden Newspaper' (a newspaper covering the Black Forest region), freiwilliges Jahr 'volunteer gap year' and soziales Jahr 'gap year for social work'. On the whole, 6o specific German A-N combinations in the data represent 56 various types.

Noun insertions present a more complex picture because embedded-language single words occur in sentences framed by the matrix language more frequently than embedded-language constituents, or islands. Hence, it is not surprising that the frequencies with which single German nouns appear in Russian discourse are more variable. Nevertheless, a sizable group of German nouns occur in bilingual sentences only sparingly, only a small portion thereof are encountered more often. Overall, 39 nouns identified in the above analysis correspond to 33 different lexemes. The frequencies with which these lexemes occur in otherwise Russian sentences are reported in Table 3. 
TABLE 3 Frequencies of German noun insertions in Russian sentences in the bilingual corpus

\begin{tabular}{lccc}
\hline $\begin{array}{l}\text { Absolute word } \\
\text { frequency }\end{array}$ & $\begin{array}{c}\text { Relative word } \\
\text { frequency }\end{array}$ & Number of lexemes & $\begin{array}{c}\text { Number of } \\
\text { lexemes, \% }\end{array}$ \\
\hline 1 & 0.00004 & 17 & 51.5 \\
2 & 0.00008 & 5 & 15.2 \\
3 & 0.00012 & 4 & 12.1 \\
4 & 0.00016 & 2 & 6.1 \\
6 & 0.00024 & 2 & 6.1 \\
7 & 0.00028 & 2 & 6.1 \\
10 & 0.00040 & 1 & 3.0 \\
\hline Total & & 33 & 100.0 \\
\hline
\end{tabular}

The table reveals that more than a half of the examined items appear embedded in Russian sentences only once. The most frequent German noun that occurs ten times in Russian discourse is Handy 'mobile phone'. The nouns with frequencies varying between five and ten include items such as $L K W$ 'truck', Mischmasch 'jumble', Spur 'lane' and Gewicht 'weight'. The observed distributions demonstrate the heterogeneity of the analyzed lexical items in term of their usage frequencies in Russian discourse.

An analysis of code-mixing which ignores the difference between nonce and recurrent insertions may be questionable and unreliable since it will rule out the possibility that embedded-language items regularly occurring in the matrix language discourse may be established loans (cf. Backus, 2013; Myers-Scotton, 1993; Poplack and Dion, 2012; Poplack, Sankoff and Miller, 1988). The distinction between items involved in code-mixing and loans has two aspects: a social aspect and a psycholinguistic aspect. From the viewpoint of the bilingual mental lexicon, borrowed forms receive the matrix language label in the mental lexicon and thus gain the status of the matrix language forms (Myers-Scotton, 1993: 207). This aspect feeds into the social aspect of borrowing, since individual linguistic practices shape the community's collective experience with language and may 
thus contribute to language change (cf. Backus, 2013). Specifically, a certain lexical item that is recurrent in the corpus may be undergoing conventionalization in Germany's variety of Russian. However, in order to investigate the spread of a linguistic structure in the community, a large representative sample is indispensable. Given the limited size of my corpus, I cannot address the issue of spread of borrowed vocabulary in the examined Russian-speaking community. Nevertheless, a renunciation of the distinction between frequently and singly occurring German lexical items in the Russian discourse will distort the picture. Therefore, I will use relative frequency as a diagnostic to discern potentially borrowed lexemes.

A practical question pertaining to the discrimination between two types of lexemes arises as to where to draw the line between items occurring more than once and frequent items, or, as Myers-Scotton puts it, "how much relative frequency is 'enough"' (Myers-Scotton, 1993: 204). Setting the cut-off threshold is usually an arbitrary decision. Myers-Scotton (1993: 207) adopts a three-occurrence rule, i.e., an item is regarded as a borrowed form if it appears at least three times in the corpus. Poplack, Sankoff and Miller (1988) suggest an absolute frequency of ten tokens for a word to count as a recurrent item and therefore a potentially established loan. The proposed solution is based on the large size of their corpus, which encompasses approximately 2.5 million words (ibid., 98). Expressed in relative terms, the threshold frequency corresponds to the value of $4 \mathrm{e}-6$. An application of this threshold to a relatively small corpus, such as mine, is not feasible because not even a single word in the corpus would count as an established loan. The frequency threshold for German noun insertions in Russian sentences was set at the relative frequency of 2e-4, which amounts to the absolute frequency of five tokens. That is, recurrent German nouns that appeared in the Russian discourse at least five times in the corpus - these included the aforementioned lexemes - were considered as potentially established loans and were thus removed from the data set. The excluded eight instances correspond to $7.9 \%$ of the data set.

In line with the previous studies of code-mixing, the bilingual corpus under scrutiny reveals that the rates at which German lone nouns are inserted into Russian sentences vary substantially. Whereas certain German nouns are used in Russian discourse only once, other items occur more frequently. The latter lexemes may represent well-established loans in the contact variety of Russian and thus contribute substantially to the heterogeneity of the sample in terms of frequency distributions. The identification of established borrowings required an operationalization of relative frequency as a diagnostic. The issue of sample heterogeneity was tackled by the removing of the established borrowings from the data set to be used in the subsequent analysis. 
In the remainder of this article, I will examine word frequency and frequency of co-occurrence of words as factors conditioning the choice that the bilingual speakers make between inserting a German adjective-modified noun phrase or producing a mixed constituent. Firstly, I will analyze the relationship between the distribution of the two alternatives in the data and the individual frequencies of the adjectives and the nouns involved in code-mixing. Secondly, by drawing on the co-occurrence frequency, I will answer the question whether the identified A-N combinations, of which the majority are German, represent recurrent collocations and could thus be regarded as lexical chunks. Finally, I will utilize a generalized linear regression model to explore the interplay between the considered factors and to evaluate their individual contributions to the total variance.

\subsection{Frequency of the Adjective}

Previous research has demonstrated that high-frequency words in the language are more accessible in production than low-frequency words (Oldfield and Wingfield, 1965), and it has located this effect on the lexeme level (Jeschiniak and Levelt, 1994). Furthermore, high-frequency words have grammatical, abstract, or general meanings (Richards, 1970: 88). The opposite also seems to hold: the less frequent a lexical item, the more specific its meaning. In other words, the frequency of a word can be viewed as a reverse function of its semantic specificity. Regarding code-mixing, Backus (1996, 2001) has observed that insertions, or embedded-language words occurring in bilingual sentences, tend to exhibit highly specific meanings. In the light of these findings, we can hypothesize that in the analyzed syntactic context, Russian adjectives combining with German noun insertions are high-frequency items with general meanings, whereas German adjectives modifying German nouns in otherwise Russian sentences are low-frequency items with specific meanings. As a corollary to this hypothesis, we may expect that the selection of rare and semantically specific adjectives may subsequently trigger the selection of successive nouns owing to their collocational strength (cf. Backus, 1996: 126).

To test this hypothesis, the frequencies of the adjectives from the identified ANP constituents were to be determined. Such a task usually requires the use of large corpora. As my bilingual corpus would not suffice for such a task, the frequencies of the examined adjectives had to be measured in a larger corpus. Hence, the measured frequencies represent approximations of the actual frequencies with which the adjectives occur in the speech of the Russian-German bilinguals. Reliable approximations are ideally obtained from a Russian and 
a German corpus of a similar size, containing texts in the same genres and modalities, such as parallel corpora. However, being small and based only on written language, parallel corpora can hardly serve as a reliable source of data for approximating frequency counts. Measuring the frequencies for all adjectives in the same corpus was thus an attractive option which enabled to avoid the discrepancies in the counts that might result from the aforementioned differences between corpora. Because the German adjectives greatly preponderate over the Russian adjectives in the data, I decided to draw on a German monolingual corpus and use German equivalents of the Russian adjectives as approximations. ${ }^{6}$

The frequencies of the adjectives were measured in (deWaC), a large German corpus containing around 1.6 billion words (Baroni and Kilgarriff, 2006). Given that this corpus is chiefly based on written language, the determined frequencies can only be considered as rough approximations of spoken language. Unfortunately, no corpus of spoken German that matches deWaC in size was available. However, considering the age and education of the participants in the study, we can assume that large portions of their German input stemmed from written sources as well.

As the next step, the frequencies were logarithmically transformed, as recommended in Baayen (2008: 31). Table 4 gives the examined nominal constituents whose adjectives have the lowest and highest usage frequencies in the corpus.

As can be seen from the table, all the adjectives in the low-frequency band are German, whereas most, but not all adjectives in the high-frequency band are Russian. This circumstance made an analysis of the data over the whole distribution necessary. The relationship between the languages of the examined adjective realizations and their frequencies is represented in Figure 1.

The variable $\mathrm{F}_{\mathrm{A}}$ on the horizontal axis is defined as frequency of the adjective on the logarithmic scale, and the vertical axis is reserved for the dependent binary variable switch placement. In the case of a phrase internal switch, the adjective is realized in Russian, and in the case of a switch outside the phrase, the adjective is realized in German. The line depicting the correlation between the two variables is a Lowess curve, which represents a function describing the deterministic part of the variation in the data and is generated by locally weighted scatterplot smoothing, a local regression method (Cleveland and

6 In Hakimov (to appear) I report that the adjectives under analysis occur in both a Russian and a German monolingual corpus at similar rates, which delivered support for the decision to utilise one corpus as a single source of frequency information in order to enhance the consistency of the counts. 
TABLE 4 German and mixed adjective-modified nominal constituents, ranked in order of lowest (above) and highest (below) frequencies of the adjectives involved; the frequencies were measured in the German deWaC corpus (for the Russian adjectives, their German equivalents were taken)

\begin{tabular}{lr} 
Noun phrase & \multicolumn{1}{c}{$\mathrm{F}_{\mathrm{A}}$} \\
\hline chillige Familie 'chilly family' & 100 \\
türkise Farbe 'turquoise color' & 175 \\
standesamtliche Hochzeit 'civil wedding ceremony' & 564 \\
gebratene Nudeln 'fried noodles' & 3,010 \\
dreckige Leute 'dirty people' & 3,204 \\
Bekannter xorošij 'good acquaintance' & $2,254,376$ \\
neue Prüfungsordnung 'new examination regulations' & $1,976,125$ \\
dal'nejšuju Information 'further information' & $1,832,696$ \\
bolšaja Flamme 'big flame' & $1,523,860$ \\
erster Freund 'first boyfriend' & $1,334,658$
\end{tabular}

Devlin, 1988). The graph shows that with the frequency of the adjective being low, the tendency is towards selecting a German adjective and thus producing a German constituent. At the same time the likelihood for realizing the adjective in German decreases with the frequency of the lexeme rising. In other words, the higher the frequency of the adjective, the higher the chance of using a Russian adjective.

In a nutshell, adjectives modifying German noun insertions in otherwise Russian sentences tend to be expressed in German if their usage frequency is low, and in Russian if their frequency is high. In order to evaluate the effect of the factor 'frequency of the adjective' on the overall variance in the data, a multifactorial analysis was conducted and its results will be presented below.

\subsection{Frequency of the Noun}

According to MacWhinney (1997: 115), interactions between lexemes can control syntactic patterns, which means that words can activate lexico-grammatical patterns in which they occur. It is thus possible that frequent words, which are more accessible in language production, can trigger other words and more abstract syntactic constructions, with which they have strong associations, more easily than infrequent words. That is, the lexico-grammatical patterns associated with high-frequency words may also be highly accessible. Regarding code-mixing in the context of the ANP constituents, we can hypothesize that high-frequency German noun can trigger their typical adjective collocates more often than low-frequency nouns. Hypothesis testing involved corpus 


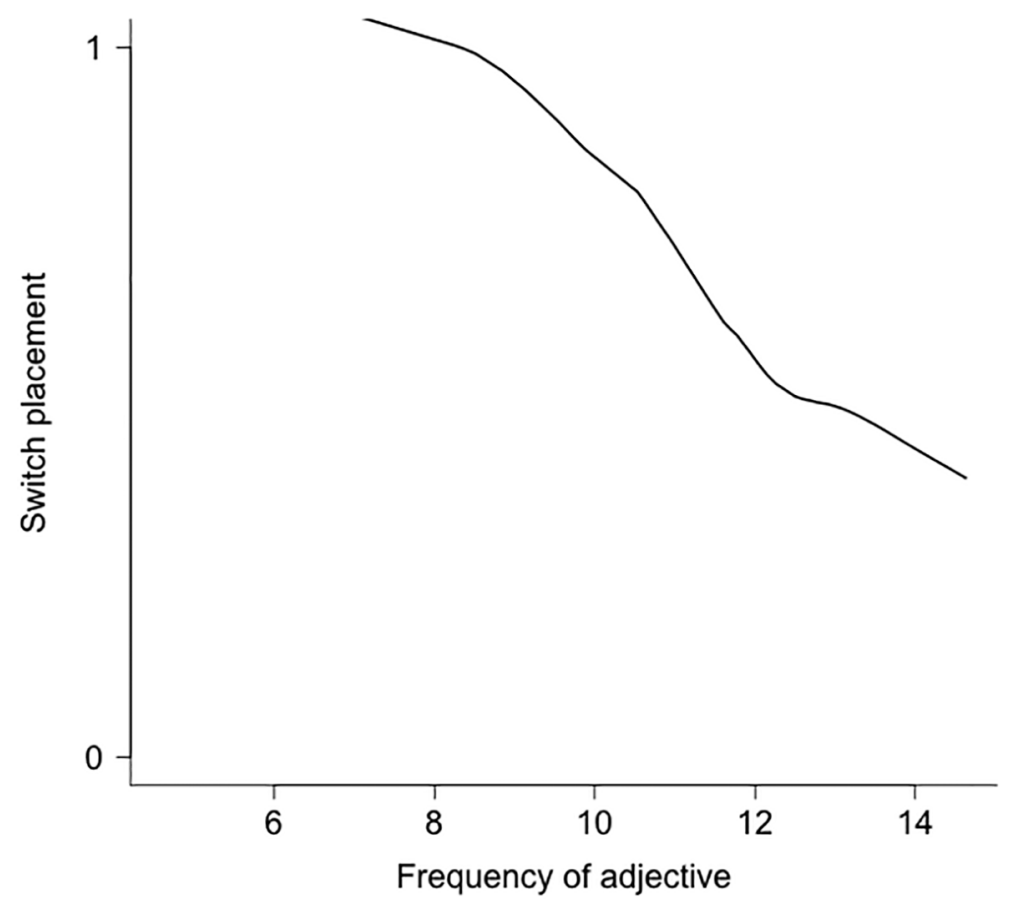

FIGURE 1 The relationship between switch placement and frequency of the adjective, as measured in deWaC. The values of $o$ and 1 on the $y$-axis stand for switching within and outside the nominal constituent, respectively. The frequency values on the $x$-axis are on the logarithmic scale

analysis again. The frequencies of the nouns under scrutiny were determined in the deWaC corpus. Table 5 details the noun phrases with nouns in the highest- and lowest-frequency range.

As can be seen from the table, German nouns in the high as well as in the low band combine with German adjectives. On the basis of the instances in the table we can conclude that to identify a tendency for the nouns in any of the bins seems impossible. Hence, it is necessary to investigate the relationship between the factors 'noun frequency' and 'switch placement' by using all the data.

A correlation between the variable noun frequency and the dependent variable 'switch placement' is represented in Figure 2. The logarithmically transformed frequency of the noun is on the horizontal axis, and the vertical axis is reserved for the binary variable 'switch placement' with the values zero and one, which stand for a switch within the phrase and a switch at the phrase boundary. The curve representing the relationship between the variables is a Lowes curve (see 5.1). The curve has a flat shape throughout most of its length, and only at the point of 10.2 on the log scale, which corresponds to 
TABLE 5 German and mixed adjective-modified nominal constituents, ranked in order of lowest (above) and highest (below) frequencies of the nouns involved; the frequencies were measured in the German deWaC corpus

Noun phrase

$\mathrm{F}_{\mathrm{N}}$

konkretnyj Meister[lehr]gang 'concrete master craftsman's course'

gefundene Kneipentour 'invented pub-crawl'

ausgebildeter Polizeihund 'trained police dog'

Weinblätter gefüllt 'filled wine-leaves'

krasiryj Saunalandschaft 'beautiful sauna facilities'

normal'naja Arbeit 'normal work'

letzte Arbeit 'last work'

soziales Jahr 'gap year for social work'

freiwilliges Jahr 'volunteer gap year'

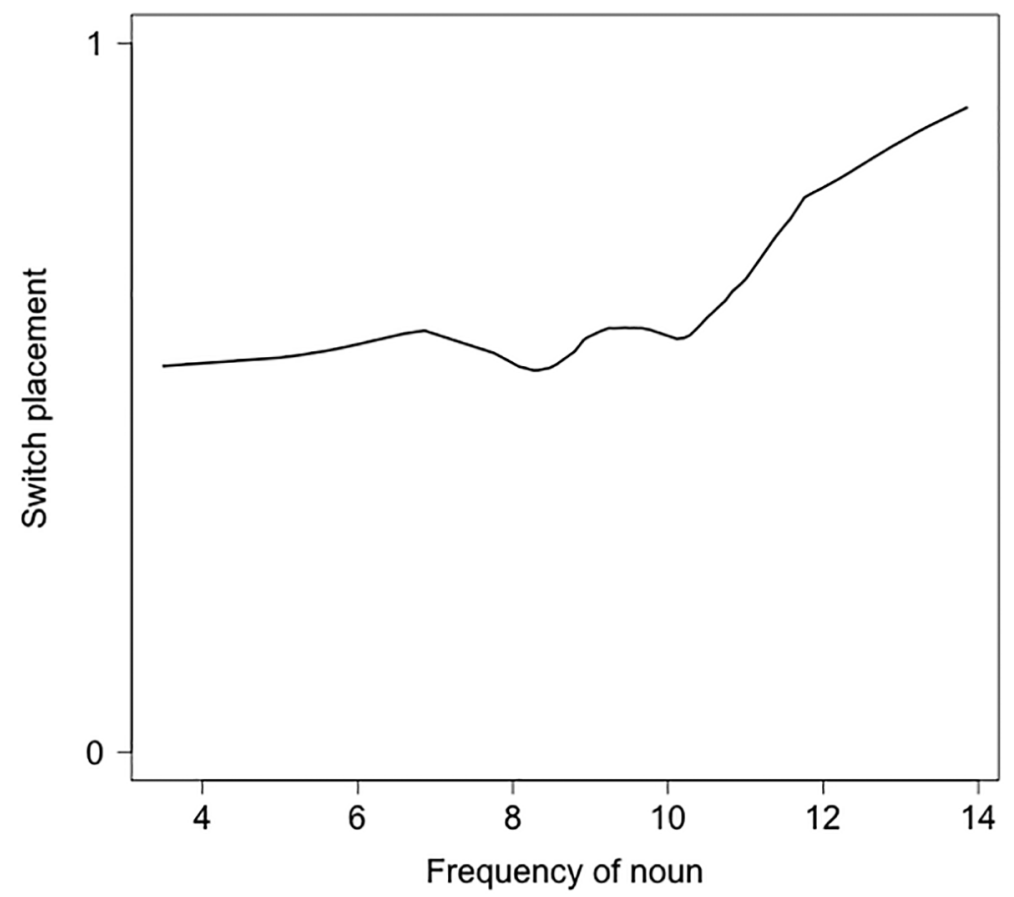

FIGURE 2 The relationship between switch placement and frequency of the noun, as measured in deWaC. The values of o and 1 on the $y$-axis stand for switching within and outside the nominal constituent, respectively. The frequency values on the $x$-axis are on the logarithmic scale 
the frequency of 26,903 in deWaC, it begins to curve upwards. In other words, noun frequency seems to exert an effect on switch placement only in the upper range of the frequency distribution. Recurrent nouns appear to co-activate adjectives that are frequently used with them in German. At the same time, a reverse effect for low-frequency nouns could not be detected. Noun frequency is evaluated below as one of the factors conditioning the variation in switch placement in the examined context.

To summarize, lexical frequency seems to influence the structure of code-mixing. German A-N combinations appear to be inserted into Russian sentences when their adjectives are low-frequency items and their nouns are on the contrary high-frequency words. However, the frequencies of the involved lexical items as measured in a German corpus would not sufficiently account for insertions of multiword units. It may well be that the unit status of a combination in the embedded language is a more relevant factor affecting the rate of multiword insertion.

\subsection{Frequency of Co-Occurrence}

According to Bybee's Linear Fusion hypothesis, which states that "items used together fuse together" (Bybee, 2002: 112), chunking is a function of the frequency of co-occurrence. We can thus conclude that a word combination counts as a multiword unit, or a lexical chunk, if the words constituting it are used together on a regular basis. Diessel (2016) attributes this effect to automatization, which is a cognitive mechanism whereby sequential activities become uncontrolled, automatic processes. Through repetition, strings of linguistic elements thus gradually become processing units, or chunks. It is necessary to complement this emergentist view of chunks by the observation that many chunks are rote learnt in the process of language acquisition (Arnon and Clark, 2011; Bannard and Matthews, 2008; Dąbrowska, 2014; Livien, Pine and Baldwin, 1997; Lieven, Salomo and Tomasello, 2009). This view is in line with Backus' hypothesis that in bilingual production words joined by a strong sequential link are accessed as a whole and inserted into sentence frames just as single lexical items (cf. Backus, 1996: 125-131, 2003).

Corpus-linguistics studies, such as Heylen and De Hertog (2014), report that corpus frequency of a word combination, or word string frequency, is a reliable indicator of its unit status in a defined syntactic context. As the present study investigates variation in switch placement in a specific syntactic context, namely the adjective-modified noun phrase, we can argue that when a specific adjective frequently appears together with a particular noun in a monolingual corpus, this recurrent $\mathrm{A}-\mathrm{N}$ combination is likely to be retrieved as a unit in bilingual production. That is, if an adjective and a noun are frequently 
activated together in monolingual use, they are likely to occur together in a bilingual clause as well. Conversely, if an adjective and a noun appear together in a corpus only occasionally, the association between them is weak, and they can thus be easily switched. In order to test these hypotheses, the frequencies of the adjective-modified nominal constituents from the bilingual corpus were measured in deWaC.

The corpus analysis of German A-N combinations was straightforward. The frequency of a specific A-N combination was determined by counting its occurrences in deWaC, whereas some of the variability pertaining to the morphological forms was disregarded. This applies to the variability resulting from the syntactic configurations in which a particular A-N combination occurs, but not to the variability conditioned by the differing values of the grammatical number since singulars and plurals may form different collocation sets (Sinclair, 2003: 167-172). The morphological variability pertains for the most part to the adjective. Its form depends on the morphological case projected on the noun phrase and on the presence/absence of preceding determiners. For example, the phrases nächst-es Jahr 'next year', (das) nächst-e Jahr, (dem) nächst-en Jahr involve the same lexemes but vary in terms of morphological marking of the adjective. Yet, they were all considered instantiations of one specific collocation for two reasons. Firstly, the combinations of these words are syntagmatically stable, i.e., [DET nächst-AG R Jahr(-GEN)], and secondly, the overall frequency of this collocation in the corpus is high. In this approach, the morphological variants of the underlying collocation were grouped together according to their number value - the singular, or the plural - and then their individual frequencies were accumulated. The same procedure was applied to combinations consisting of a Russian adjective and a German noun, but in this case, German equivalents of the Russian adjectives were used.

The results for ten most frequent A-N combinations are given in Table 6. As detailed in Table 6, the listed high-frequency A-N combinations, with one exception, repel switching. Even taking into account that exception, namely the mixed phrase sledujuščij Tag 'next day', the general tendency is in line with the proposed hypothesis. Conversely, German nouns with weak or no collocational ties to specific German adjectives will freely combine with Russian adjectives to produce bilingual A-N combinations. However, the results of the corpus analyses are not so straightforward. Table 7 lists the combinations of nouns and adjectives whose co-occurrence frequencies as measured in deWaC are in the lowest range.

The table contains five mixed and five German A-N combinations. Considering the low frequencies of these combinations, it could be argued that they represent free word combinations. The only obvious exception to 
TABLE 6 German and mixed adjective-modified nominal constituents with the highest frequencies of occurrence in the deWaC corpus

\begin{tabular}{lc} 
Noun phrase & $\mathrm{F}_{\mathrm{A}-\mathrm{N}}$ \\
\hline nächstes Jahr 'next year' & 27,785 \\
sledujuščij Tag 'next day' & 22,927 \\
katholische Kirche 'Catholic Church' & 20,856 \\
nächste Woche 'next week' & 10,499 \\
erstes Semester 'first term' & 3,185 \\
gute Nacht 'good night' & 3,031 \\
nationale Identität 'national identity' & 2,879 \\
alte Bundesländer 'old federal states (of Germany)' & 1,445 \\
letzte Arbeit 'last work' & 1,262 \\
bares Geld 'cash money' & 1,148 \\
\hline
\end{tabular}

TABLE 7 German and mixed adjective-modified nominal constituents with the lowest frequencies of occurrence in the deWaC corpus

\begin{tabular}{ll}
\hline Noun phrase & $\mathrm{F}_{\mathrm{A}-\mathrm{N}}$ \\
\hline russische Party 'Russian party' & 3 \\
krasiryj Saunalandschaft 'beautiful sauna facilities' & 3 \\
ausgebildeter Polizeihund 'trained police dog' & 3 \\
bednyj Hausmeister 'poor caretaker' & 2 \\
real'naja Schlampe 'real slut' & 2 \\
Schlampe redkostnaja 'rare slut' & 2 \\
normales Klo 'normal loo' & 1 \\
lebendes Fragezeichen 'living question mark' & 1 \\
novyj Trockner 'new drier' & 1 \\
süße Grußkarte 'sweet greeting card' & 1 \\
\hline
\end{tabular}

this tendency is the combination ausgebildeter Polizeihund 'trained police dog', which may be regarded as a lexical chunk owing to its semantic coherence. Only eight A-N combinations from the bilingual corpus were not attested in deWaC. Among them are both German and mixed combinations such as chillige Familie 'relaxed family', freie Bundesländer 'free federal states', ogromnyj Titel 'huge header', sportivnye Sachen 'sporty things' and obšcij Hochdeutsch 'general Standard German'. Despite their non-attestation in deWaC, the eight 
instances were not discarded in the subsequent statistical analysis, which was performed on the whole data set.

To identify and evaluate the contribution of the individual factors $\mathrm{F}_{\mathrm{N}^{\prime}} \mathrm{F}_{\mathrm{A}}$ and $\mathrm{F}_{\mathrm{A}-\mathrm{N}}$ and their possible interactions to the reported variation in switch placement, a logistic regression analysis was used. The generalized linear mixed-effects model, which is used in this study, calculates the effects of individual predictors on a binary dependent variable as both fixed and random effects under multivariate control (cf. Baayen, 2008: 278-284). The fixed-effect factors are the aforementioned measured frequency data, the random-effect factor is "speaker". As Tagliamonte and Baayen (2012) point out, this predictor may become very influential and distort the effect of fixed-effect predictors because each individual speaker in a sample contributes a different number of observations.

The statistics package $\mathrm{R}$ version 2.12.o ( $\mathrm{R}$ Core Team, 2010) was used to carry out logistic regression analysis and all other statistical tests, and to generate graphical plots.

The minimal adequate model, which provides the best fit to the data, is reported in Table 8. As can be seen from the table, the model is rather accurate since it correctly classifies 82 per cent of all instances of switch placement in the data set, while the baseline model, which always predicts the most frequent case, i.e., switch placement at the phrase boundary, is only accurate in 65 per cent of the instances. The $C$ index, estimating the probability of concordance between predicted and observed choices, is 0.903 , which indicates a high predictive power of the minimal adequate model, and the performance indicator Somers' $D x y$, related to the $C$ index, suggests a good fit $(D x y=0.805)$.

The minimal adequate model included the predictors "adjective frequency" and "co-occurrence frequency" as fixed-effect factors and the predictor 'speaker' as the random factor. The predictor "noun frequency" as a fixed factor as well as possible interactions between the fixed-effect factors were found to decrease the minimal adequate model's predictive capacity and were thus discarded. The predicted odds, as reported in Table 8 , are for the switches placed at the boundary of the modified nominal constituent. The positive coefficient of the frequency with which an adjective and a noun appear together (o.374) indicates that this predictor enhances the probability of a switch at the phrase boundary. The frequency of the adjective is related to the likelihood of such a 
TABLE 8 Predicting switch placement in the context of the adjective-modified nominal constituent: minimal adequate generalized linear mixed model. Predicted odds are for switch placement outside the constituent. Significance code: * significant at $p<$ $0.05,{ }^{* *} p<.01,{ }^{* * *} p<.001$

\begin{tabular}{lccccc}
\hline Factor & Estimate & Std. error & $z$ & $\operatorname{Pr}(>|z|)$ \\
\hline $\begin{array}{l}\text { Intercept) } \\
\text { Frequency of }\end{array}$ & 10.237 & 2.795 & 3.662 & $<0.001$ & $* * *$ \\
$\quad$ co-occurrence & 0.374 & 0.109 & 3.422 & 0.001 & $* * *$ \\
Frequency of A & -0.919 & 0.233 & -3954 & $<0.001$ & $* * *$ \\
\hline
\end{tabular}

Random effect:

Speaker

(intercept, $\mathrm{N}=17$, variance $=0.999, \sigma=0.999$ )

\section{Summary statistics:}

$\mathrm{N}$

91

$\%$ correct predictions (\% baseline)

$C$ index of concordance

Somers' Dxy
$82(65)$

0.903

0.805

switch negatively (-o.919), i.e., the probability of a switch at the phrase boundary grows with the adjective frequency decreasing. More specifically, if the adjective is infrequent, but the A-N combination is of recurrent use in German, the likelihood of inserting this combination as a chunk is high, as in the case of bares Geld 'cash money' and alleinerziehende Mutter 'single mother'. However, when the adjective is a high-frequency word and it collocates with the head noun only occasionally, the chance of switching from Russian to German within the nominal constituent is increased, as in the case of ogromnyj Trockner 'huge drier' and russkij Besitzer 'Russian owner'. As to the random-effect predictor 'speaker', judging by its variance and the corresponding standard deviation we assert that differences among the speakers with regard to their preference for one of the two switching patterns are negligible.

\section{7}

\section{Discussion}

The analysis of adjective-modified nominal constituents in Russian-German bilingual speech revealed that German nominal constituents frequently occur in otherwise Russian sentences. In their vast majority, they are well-formed German nominal constituents, of which only a fraction are fully-fledged noun 
phrases. The bulk of the German nominal constituents inserted in Russian sentences lack German determiners in obligatory contexts, but their internal structure is clearly German because gender-number agreement is consistently maintained. The tendency to preserve the internal structure in inserted German nominal constituents and to omit German determiners may be interpreted as one of the strategies that bilinguals employ in order to enhance structural equivalence between the languages in contact. The other frequent type of nominal constituents under analysis are mixed nominal constituents consisting of German nouns and Russian attributive adjectives. The analysis of the bilingual corpus demonstrated that these constituents form a smaller, but still substantial group. Hence, two types of ANP constituents were attested in Russian-German bilingual sentences: German nouns modified by German attributive adjectives and German nouns modified by Russian attributive adjectives. That is, a bilingual speaker may select and realize the adjective in Russian or in German.

The results of the analysis allowed me to respond to the main research question, i.e., the question whether lexical factors, such as collocational ties between words and word frequency, may account for variation in syntactic patterns of code-mixing in the context of the adjective-modified nominal constituent. The findings indicate that these factors strongly affect the choice between the two patterns in Russian-German bilingual speech. However, of the considered factors, which included the frequency of the noun, the frequency of the adjective and the frequency of their co-occurrence in German, the combination of only the frequency of the adjective and the frequency of co-occurrence appeared to reliably predict the examined variation and to thus account for the patterns in switch placement in the data set. If the frequency of the adjective, the most important factor in the statistical model, is low, the probability is high that a German monolingual constituent such as türkise Farbe 'turquoise color' will emerge, regardless of the frequency of co-occurrence. If values of both factors are high, a German nominal constituent such as nächstes Jahr 'next year' is likely, but a bilingual, or mixed, constituent such as dal'nejšuju Information 'further information' is not entirely improbable. Finally, if only the frequency of the adjective is high but the frequency of co-occurrence is low, a mixed constituent is a serious possibility; examples of the latter type include the phrases ogrommyj Trockner 'huge dryer' and krasiryj Saunalandschaft 'beautiful sauna facilities'.

The findings of this study include two frequency effects. The frequency of an adjective affects switch placement in that most of the high-frequency adjectives in the examined context come from Russian. This is not surprising because Russian is a more strongly activated language and the source of 
high-frequency words and grammatical elements, which are distinguished by easy accessibility and very general meanings. Attributive adjectives of average and low frequencies, which have specific meanings, are primarily German. This observation provides evidence for Backus' $(1996,2001)$ specificity continuum hypothesis introduced in section 5.1, according to which anotherlanguage items with specific meanings are commonplace in bilingual speech, particularly at early stages of contact, as is the case in the current study. As regards online production, we may conclude that whenever a very specific German adjective of average or low frequency is activated and accessed, it co-activates, or triggers, the head noun in the same language. This may be to the fact that in German, an inflected adjective sets a strong projection with regard to the nature of the following element, which must be a noun (Auer, 2007b: 98; cf. Auer, 2005). It is important to emphasize that co-activation spreads from the adjective to the noun and not vice versa because not a single German adjective appears to modify a Russian noun in the RussianGerman bilingual data, i.e., each inflected German adjective is followed by a German noun, but German nouns freely combine with Russian adjectives. These results shed light on the degrees of activation of the German lexicon/ grammar during the processing of the examined constituents. As the adjectives that modify German nouns in otherwise Russian sentences are mainly German and their accessibility in processing, owing to their low and average frequencies of use, is restricted, we may assume that the German lexicon/grammar is highly activated when German nominal constituents, or the so-called embedded-language islands, are produced. In other words, the German lexicon/grammar seems to be more strongly activated since it delivers very specific adjectives and is responsible for the co-activation effect. When German is only the source of nouns involved in bilingual, or mixed, nominal constituents, the activation of German lexicon/grammar is lower. Hence, the effect of the lexical frequency on the choice between a German monolingual constituent and a mixed Russian-German constituent offers indirect support for Myers-Scotton's (2002: 140) view that the production of embedded-language islands and the production of single embedded-language elements occurring in the matrix language frame require different levels of activation of the embedded language.

The effect of the frequency with which adjectives and nouns appear together in German, which has been referred to as "co-occurrence frequency", is another significant result of this study. The regression analysis revealed that German words that are regularly used together in the German monolingual corpus repel switches, whereas word combinations with loose collocational ties appear to attract switches. Psycholinguistic studies using 
behavioral (Arnon and Snider, 2010; Janssen and Barber, 2012) and neurophysiological data (Tremblay and Baayen, 2010) report a facilitating effect of co-occurrence frequency, or phrase frequency, on online language processing and suggest that frequently used multiword sequences are apparently stored and retrieved as holistic units, just as monomorphemic words. This suggests that whenever a representation that corresponds to a recurrent A-N combination is activated, it is accessed and retrieved as a whole. The statistically significant effect of co-occurrence frequency is consistent with the prediction of the unit hypothesis proposed by Backus (1996, 2003), according to which embedded-language islands correspond to units in the mental lexicon. However, as has been indicated above, embedded-language islands structured as German adjective-modified nominal constituents may also emerge because of co-activation, or triggering. Therefore, two mechanisms responsible for the emergence of embedded-language islands should be distinguished, namely retrieval of a representation corresponding to a lexical chunk and co-activation. From this perspective, I suggest a weaker version of the unit hypothesis, namely that not all, but many embedded-language islands are lexical chunks.

\section{$8 \quad$ Conclusion}

This study investigates the variation in code-mixing patterns in the context of the adjective-modified noun phrase and the factors contributing to this variation. The analysis of the Russian-German bilingual corpus revealed that German nouns combine with Russian and German attributive adjectives to form either Russian-German bilingual nominal constituents or German monolingual nominal constituents, which correspond to well-formed embedded-language islands. I presented linguistic arguments and empirical evidence that usage frequency accounts for the emergence of embedded-language islands in bilingual speech. Specifically, I found evidence to suggest that the frequency of the adjective and the frequency of the A-N combination in German account for the occurrence of German monolingual adjective-modified nominal constituents in otherwise Russian sentences. This evidence was based on frequency measurements in a large German corpus and statistical analysis. The effect of co-occurrence frequency indicates that a great part of the A-N insertions can be regarded as units in the mental lexicon in Backus' (2003) sense. Yet, the rate of such insertions in the data was also found to depend on the adjective frequency in the low and medium band. Low- and medium-frequency adjectives tended to occur with German nouns even in the absence of collocational 
bonds. In light of this evidence, I suggested two mechanisms underlying the emergence of embedded-language islands, namely retrieval of a represented multiword chunk and co-activation. Finally, I proposed a weaker version of Backus' unit hypothesis, namely that many but not all embedded-language islands correspond to multiword chunks, which are retrieved holistically from the mental lexicon/grammar. It follows from the presented evidence that experience-based factors such as frequency of use reliably predict patterns of variation in code-mixing and effectively account for the emergence of embedded-language islands, although their occurrence has often been attributed to solely structural factors, such as lack of congruence between the lemmas in the involved languages. However, considering a number of existing overlaps between Russian and German in patterns of syntactic modification, it was impossible to orthogonalize the factors related to grammatical congruence and those pertaining to usage. Therefore, future work should determine the effects of structural (dis)similarity and usage frequency on patterns of code-mixing between languages that are genetically and/or typologically more distant. At the same time, I assume that lexical frequency and co-occurrence frequency will reliably account for the emergence of embedded-language islands in those contact situations as well.

\section{References}

Arnon, Inbal and Eve V. Clark. 2011. Why brush your teeth is better than teeth - children's word production is facilitated in familiar sentence-frames. Language Learning and Development 7(2): 107-29.

Arnon, Inbal and Neal Snider. 2010. More than words: Frequency effects for multi-word phrases. Journal of Memory and Language 62(1): 67-82.

Auer, Peter. 2005. Projection in interaction and projection in grammar. Text Interdisciplinary Journal for the Study of Discourse 25(1): 7-36.

Auer, Peter. 2007a. Why are increments such elusive objects? An afterthought. Pragmatics 17(4): 647-658.

Auer, Peter. 2007b. Syntax als Prozess. In Heiko Hausendorf (ed.), Gespräch als Prozess. Linguistische Aspekte der Zeitlichkeit verbaler Interaktion, 95-124. Tübingen: Narr.

Auer, Peter. 2014. Language mixing and language fusion: When bilingual talk becomes monolingual. In Besters-Dilger, Juliane, Cynthia Dermarkar, Stefan Pfänder and Achim Rabus (eds.), Congruence in contact-induced language change: Language families, typological resemblance, and perceived similarity, 294-334. Berlin, Boston: De Gruyter. 
Baayen, Harald R. 2008. Analyzing linguistic data. Cambridge, UK; New York: Cambridge University Press.

Backus, Ad. 1992. Patterns of language mixing. A study in Turkish-Dutch bilingualism. Wiesbaden: Harrassowitz.

Backus, Ad. 1996. Two in one: Bilingual speech of Turkish immigrants in the Netherlands. Tilburg, Netherlands: Tilburg University Press.

Backus, Ad. 1999. Evidence for lexical chunks in insertional codeswitching. In Brendemoen, Bernt, Elizabeth Lanza and Else Ryen (eds.), Language encounters across time and space: Studies in language contact, 93-109. Oslo: Novus.

Backus, Ad. 2001. The role of semantic specificity in insertional codeswitching: Evidence from Dutch-Turkish. In Jacobson, Rodolfo (ed.), Codeswitching Worldwide II, 125-54. Berlin; New York: De Gruyter.

Backus, Ad. 2003. Units in code switching: Evidence for multimorphemic elements in the lexicon. Linguistics 41(1): 83-132.

Backus, Ad. 2013. A usage-based approach to borrowability. In Zenner, Eline and Gitte Kristiansen (eds.), New perspectives on lexical borrowing: Onomasiological, methodological and phraseological innovations, 19-40. Berlin, Boston: De Gruyter.

Bannard, Colin, and Danielle Matthews. 2008. Stored word sequences in language learning: The effect of familiarity on children's repetition of four-word combinations. Psychological Science 19(3): 241-248.

Baroni, Marco, and Adam Kilgarriff. 2006. Large linguistically-processed web corpora for multiple languages. In Proceedings of the 11th Conference of the European Chapter of the Association for Computational Linguistics (EACL 2006). Trento, Italy., 87-9o. Morristown, NJ: Association for Computational Linguistics.

Berk-Seligson, Susan. 1986. Linguistic constraints on intrasentential code-switching: A study of Spanish/Hebrew bilingualism. Language in Society 15(3): 313-348.

Boumans, Louis. 1998. The syntax of codeswitching: Analysing Moroccan Arabic/Dutch conversation. Tilburg: Tilburg University Press.

Brehmer, Bernhard. 2007. Sprechen Sie Qwelja? Formen und Folgen russisch-deutscher Zweisprachigkeit in Deutschland. In Anstatt, Tanja (ed.), Mehrsprachigkeit bei Kindern und Erwachsenen: Erwerb, Formen, Förderung, 163-185. Tübingen: Attempto-Verlag.

Bybee, Joan L. 2002. Sequentiality as the basis of constituent structure. In Givón, Talmy and Bertram F. Malle (eds.), The evolution of language out of pre-language, 107-132. Amsterdam; Philadelphia, PA:John Benjamins.

Bybee, Joan L. 2006. From usage to grammar: The mind's response to repetition. Language 82(4): 711-733.

Bybee, Joan L. 2010. Language, usage and cognition. Cambridge, UK; New York: Cambridge University Press. 
Cantone, Katja Francesca and Jeff MacSwan. 2009. Adjectives and word order: A focus on Italian-German codeswitching. In Isurin, Ludmila, Donald Winford and Kees De Bot (eds.), Multidisciplinary approaches to code switching, 243-277. Amsterdam, Philadelphia, PA: John Benjamins.

Cleveland, William S. and Susan J. Devlin. 1988. Locally weighted regression: An approach to regression analysis by local fitting. Journal of the American Statistical Association 83(403): 596-610.

Dąbrowska, Ewa. 2014. Recycling utterances: A speaker's guide to sentence processing. Cognitive Linguistics 25(4): 617-653.

Deuchar, Margaret. 2005. Congruence and Welsh-English code-switching. Bilingualism: Language and Cognition 8(3): 255-269.

Deuchar, Margaret. 2006. Welsh-English code-switching and the Matrix Language Frame Model. Lingua 116(11): 1986-2011.

Diessel, Holger. 2016. Frequency and lexical specificity. A critical review. In Behrens, Heike, and Stefan Pfänder (eds.), Experience counts: Frequency effects in language, 209-237. Berlin, Boston: De Gruyter.

Dietz, Barbara. 20o6. Aussiedler in Germany: From smooth adaptation to tough integration. In Lucassen, Leo, David Feldman and Jochen Oltmer (eds.), Paths of integration - Migrants in Western Europe (1880-2004), 116-136. Amsterdam: Amsterdam University Press.

Dryer, Matthew S. 2013. Order of adjective and noun. In Dryer, Matthew S. and Martin Haspelmath (eds.), The world atlas of language structures online. Leipzig: Max Planck Institute for Evolutionary Anthropology. https://wals.info/chapter/87. (Accessed June 6th, 2016.)

Dürscheid, Christa. 2002. „Polemik satt und Wahlkampf pur“ - Das postnominale Adjektiv im Deutschen. Zeitschrift für Sprachwissenschaft 21(1): 57-81.

Eisenberg, Peter. 1999. Grundriss der deutschen Grammatik. Vol. 2: Der Satz. Stuttgart; Weimar: Metzler.

Field, Fredric W. 2002. Linguistic borrowing in bilingual contexts. Amsterdam; Philadelphia, PA: John Benjamins.

Gardner-Chloros, Penelope. 1991. Language selection and switching in Strasbourg. Oxford, New York: Clarendon Press; Oxford University Press.

Hakimov, Nikolay. To appear. Explaining Russian-German code-mixing: A usage-based approach to code-mixing. Language Science Press: Berlin.

Hakimov, Nikolay. 2016a. Explaining variation in plural marking of German noun insertions in Russian sentences. In Behrens, Heike and Stefan Pfänder (eds.), Experience counts: Frequency effects in language, 21-6o. Berlin, Boston: De Gruyter.

Hakimov, Nikolay. 2016b. Effects of frequency and word repetition on switch-placement: Evidence from Russian-German code-mixing. In Robinson, Justyna A. and Monika Reif (eds.), Culture and cognition in bilingualism, 91-125. Berlin, Boston: De Gruyter. 
Halmari, Helena. 1997. Government and codeswitching: Explaining American Finnish. Amsterdam; Philadelphia, PA:John Benjamins.

Haust, Delia. 1995. Codeswitching in Gambia: Eine soziolinguistische Untersuchung von Mandinka, Wolof und Englisch in Kontakt. Köln: Rüdiger Köppe.

Heylen, Kris, and Dirk De Hertog. 2014. Automatic term extraction. In Hendrik J. Kockaert and Frieda Steurs (eds.), Handbook of Terminology, 199-219. Amsterdam; Philadelphia, PA: John Benjamins.

Hlavac, Jim. 2003. Second-generation speech: Lexicon, code-switching and morphosyntax of Croatian-English bilinguals. Frankfurt am Main; Berlin; Bern; Bruxelles; New York; Oxford; Wien: Peter Lang.

Janssen, Niels and Horacio A. Barber. 2012. Phrase frequency effects in language production. PLoS ONE 7(3): e33202.

Jeschiniak, Niels and Willem J. M. Levelt. 1994. Word frequency effects in speech production: Retrieval of syntactic information and phonological form. Journal of Experimental Psychology: Learning, Memory, and Cognition 20: 824-843.

Langacker, Ronald W.1987. Foundations of Cognitive Grammar: TheoreticalPrerequisites. Vol. 1 of 2 vols. Stanford, CA.: Stanford University Press.

Lapteva, Olga A. 1976. Russkij razgovornyj sintaksis. [Russian spoken syntax.]. Moscow: Nauka.

Lieven, Elena V. M., Julian M. Pine and Gillian Baldwin. 1997. Lexically-based learning and early grammatical development. Journal of Child Language 24(1):187-219.

Lieven, Elena, Dorothé Salomo and Michael Tomasello. 20o9. Two-year-old children's production of multiword utterances: A usage-based analysis. Cognitive Linguistics $20(3): 481-507$.

MacWhinney, Brian. 1997. Second language acquisition and the competition model. In Kroll Judith F. and Annette M. B. de Groot (eds.), Tutorials in bilingualism, 113-142. Mahwah, NJ: Lawrence Erlbaum.

McClure, Erica F.1977. Aspects of code-switching in the discourse of bilingual MexicanAmerican children. Urbana, IL: University of Illinois at Urbana-Champaign.

Meng, Katharina. 2001. Russlanddeutsche Sprachbiografien: Untersuchungen zur sprachlichen Integration von Aussiedlerfamilien. Tübingen: Narr.

Miller, Jim. E. and Regina Weinert. 1998. Spontaneous spoken language: Syntax and discourse. Oxford; New York: Oxford University Press.

Muhamedowa, Raihan. 20o6. Untersuchung zum kasachisch-russischen Code-mixing (mit Ausblicken auf den uigurisch-russischen Sprachkontakt). München: Lincom Europa.

Muysken, Pieter. 200o. Bilingual speech: A typology of code-mixing. Cambridge, UK; New York: Cambridge University Press.

Myers-Scotton, Carol. 1993. Duelling languages: Grammatical structure in codeswitching. Oxford; New York: Clarendon Press; Oxford University Press. 
Myers-Scotton, Carol. 2002. Contact linguistics: Bilingual encounters and grammatical outcomes. Oxford, New York: Oxford University Press.

Myers-Scotton, Carol and Janice L. Jake. 1995. Matching lemmas in a bilingual language competence and production model: Evidence from intrasentential code-switching. Linguistics 33: 981-1024.

Nortier, Jacomine. 1990. Dutch-Moroccan Arabic code switching among Moroccans in the Netherlands. Dordrecht, Holland; Providence, RI: Foris.

Oldfield, Richard Ch. and Arthur Wingfield. 1965. Response latencies in naming objects. Quarterly Journal of Experimental Psychology 17(4): 273-281.

Parafita Couto, Maria del Carmen, Margaret Deuchar and Marika Fusser. 2015. How do Welsh-English bilinguals deal with conflict? Adjective-noun order resolution. In Stell, Gerald and Kofi Yakpo (eds.), Code-switching between structural and sociolinguistic perspectives, 65-84. Berlin; Boston: De Gruyter.

Pfaff, Carol W. 1979. Constraints on language mixing: Intrasentential code-switching and borrowing in Spanish/English. Language 55(2): 291-318.

Poplack, Shana. 1980. Sometimes I'll start a sentence in Spanish y termino en Español: Toward a typology of code-switching. Linguistics 18(7/8): 581-618.

Poplack, Shana and Nathalie Dion. 2012. Myths and facts about loanword development. Language Variation and Change 24(3): 279-315.

Poplack, Shana and Marjorie Meechan. 1995. Patterns of language mixture: Nominal structure in Wolof-French and Fongbe-French bilingual discourse. In Milroy, Lesley and Pieter Muysken (eds.), One speaker, two languages: Cross-disciplinary perspectives on code-switching, 199-232. Cambridge, UK; New York: Cambridge University Press.

Poplack, Shana, David Sankoff, and Christopher Miller. 1988. The social correlates and linguistic processes of lexical borrowing and assimilation. Linguistics 26(1): 47-104.

R Core Team. R: A Language and Environment for Statistical Computing. R Foundation for Statistical Computing. Vienna, 2010. www.R-project.org.

Richards, Jack C. 1970. A psycholinguistic measure of vocabulary selection. IRAL International Review of Applied Linguistics in Language Teaching 8(2): 87-102.

Riehl, Claudia Maria. 2017. Russian-Germans: Historical background, language varieties, and language use. In Isurin, Ludmila and Claudia Maria Riehl (eds.), Integration, identity and language maintenance in young immigrants: Russian Germans or German Russians, 11-40. Amsterdam; Philadelphia, PA:John Benjamins.

Sankoff, David, Shana Poplack and Swathi Vanniarajan. 199o. The case of the nonce loan in Tamil. Language Variation and Change 2(1): 71-101.

Schneider, Ulrike. 2016. Chunking as a factor determining the placement of hesitations: A corpus-based study of spoken English. In Behrens, Heike and Stefan Pfänder (eds.), Experience Counts: Frequency Effects in Language, 61-9o. Berlin; Boston: De Gruyter. 
Sinclair, John McHardy. 2003. Reading concordances: An introduction. London; New York: Pearson/Longman.

Stefanowitsch, Anatol and Susanne Flach. 2016. A corpus-based perspective on entrenchment. In Schmid, Hans-Jörg (ed.), Entrenchment and the psychology of language learning: How we reorganize and adapt linguistic knowledge, 101-128. Berlin; Boston: De Gruyter.

Švedova, Natalia Jul'evna (ed.). 2005/198o. Russkaja grammatika [Russian grammar]. Vol. 1: Fonetika, fonologija, udarenie, intonatsija, slovoobrazovanije, morfologija [Phonetics, phonology, stress, intonation, word formation, morphology]. Moscow: Institut russkogo jazyka im. V.V. Vinogradova.

Szabó, Csilla Anna. 2010. Language shift und Code-mixing: Deutsch-ungarischrumänischer Sprachkontakt in einer dörflichen Gemeinde in Nordwestrumänien. Frankfurt am Main; Berlin; Bern; Bruxelles; New York; Oxford; Wien: Peter Lang.

Tagliamonte, Sali A. and R. Harald Baayen. 2012. Models, forests, and trees of York English: was/were variation as a case study for statistical practice. Language Variation and Change 24(2): 135-178.

Tomasello, Michael. 2003. Constructing a language: A usage-based theory of language acquisition. Cambridge, MA.; London, UK: Harvard University Press.

Treffers-Daller, Jeanine. 1994. Mixing two languages: French-Dutch contact in a comparative perspective. Berlin; New York: Mouton De Gruyter.

Tremblay, Antoine and Harald R. Baayen. 2010. Holistic processing of regular fourword sequences: A behavioral and ERP study of the effects of structure, frequency, and probability on immediate free recall. In Wood, David (ed.), Perspectives on formulaic language: Acquisition and communication, 151-173. London, UK; New York: Continuum.

van Hout, Roeland and Pieter Muysken. 1994. Modeling lexical borrowability. Language Variation and Change 6(1): 39-62.

Wurzel, Wolfgang Ullrich. 1984. Flexionsmorphologie und Natürlichkeit. Berlin: Akademie Verlag.

Zemskaja, Elena A. 1987. Russkaja razgovornaja reč’: Lingvističeskij analiz i problemy obučenija. [Russian spoken speech: Linguistic analysis and issues of language education.]. 2nd ed. Moscow: Russkij jazyk.

Zifonun, Gisela, Ludger Hoffmann, Bruno Strecker and Joachim Ballweg. 1997. Grammatik der deutschen Sprache. Vol. 3 of 3 vols. Berlin; New York: De Gruyter. 